\title{
Correlation of learning disabilities to porn addiction based on EEG
}

\author{
Norhaslinda Kamaruddin', Nurul Izzati Mat Razi ${ }^{2}$, Abdul Wahab \\ ${ }^{1}$ Faculty of Computer and Mathematical Sciences, Universiti Teknologi MARA, Selangor, Malaysia \\ ${ }^{1}$ Fakultas Sains dan Teknologi, Kampus C, Universitas Airlangga, Indonesia \\ ${ }^{2,3}$ Kulliyah of Information and Communication Technology, International Islamic University Malaysia, Malaysia
}

\begin{tabular}{l} 
Article Info \\
\hline Article history: \\
Received Apr 8, 2020 \\
Revised Jun 11, 2020 \\
Accepted Jul 29, 2020 \\
\hline
\end{tabular}

\section{Keywords:}

Attention deficit hyperactivity disorder (ADHD)

Autism spectrum disorder

(ASD)

Dyslexia

Learning disorder

Neurophysiological

Porn addiction

\begin{abstract}
Researchers were able to correlate porn addiction based on electroencephalogram (EEG) signal analysis to the psychological instruments' findings. In this paper we attempt to correlate the porn addiction to various cases of learning disorders through analyzing EEG signals. Since porn addiction involved the brainwave power at the frontal of the brain, which reflects the executive functions, this may have correlation to learning disorder. Only three types of learning disorder will be of interest in our study involving dyslexic, attention deficit and hyperactivity disorder (ADHD) and autistic children because they involved reduced intellectual ability observed from the lack of listening, speaking, reading, writing, reasoning, or mathematical proficiencies. Children with such disorder when expose to the internet unfiltered porn contents may have minimal understanding of the negative effects of the contents. Such unmonitored exposure to pornographic contents may result to porn addiction because it may trigger excitement and induced pleasure. Experimental results show strong correlation of learning disorders to porn addiction, which can be worthwhile for further analysis. In addition, this paper also indicates that analyzing brainwave patterns could provide a better insight into predicting and detecting children with learning disorders and addiction with direct analysis of the brain wave patterns.
\end{abstract}

This is an open access article under the CC BY-SA license.

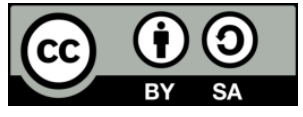

\section{Corresponding Author:}

Norhaslinda Kamaruddin,

Advanced Analytics and Engineering Center,

Faculty of Computer and Mathematical Sciences,

UniversitiTeknologi MARA,

40450 Shah Alam, Selangor, Malaysia.

Email: norhaslinda@fskm.uitm.edu.my

\section{INTRODUCTION}

Most children with learning disorders have one or more functional limitation that may involves cognitive, developmental, intellectual, mental, physical, sensory, and/or combination of these attributes. It is reported that over 1 billion people or approximately $15 \%$ of the world population experienced disorder globally. From this statistic, Malaysia recorded 531,962 and 494,074 cases in 2014 and 2013 respectively with $7.67 \%$ increment of the reported cases [1]. Report by Department of Social Welfare further elaborated that 35\% of the disorder cases in 2014 were from learning disorder followed by physical (33\%), hearing (12\%), vision (9\%), others (5\%), mental (5\%) and speech impairments (1\%) [2]. Learning disorder (LD) symptoms can be lack of listening and speaking, difficulty with reading, writing, reasoning, remembering, paying attention, following directions, solving mathematical problems, staying organized and poor in coordination [3]. Recent study by Mesibov and Sreckovic reported that individual with autism spectrum 
disorder (ASD) may be exposed to an illegal situation such as the invitations to access child pornography [4]. Such situation may allow irresponsible people to accuse them to be a pedophile. This may happen because the individual with ASD may not realize the bad implication of pornography exploitation. McCabe and Cummins stated that individual with LD may not be able to censoriously think about pornography due to their cognitive abilities [5]. Malaysian communications and multimedia commission (MCMC) Internet Users Survey in 2018 reported approximately 28.7 million internet users that comprised of $93.1 \%$ of Malaysia population are actively connected to the Internet [6]. The survey also reported that $83.2 \%$ of children age 5 to 17 were Internet users whom $93 \%$ of them access Internet through smartphone in 2016. Hence, it is not surprising if young children can easily access pornography and such observation is in-line with the recent survey conducted by the national society for prevention of cruelty to children (NSPCC) and Middlesex University on 1,000 children aged 11-16 across the United Kingdom found 94\% of the participants have accessed pornography by the age of 14 [7]. The easy accessibility of pornographic contents may encourage the tendency to become porn addiction. Such situation is even more fatal for individual with learning disorders as individual with LD is always seen to be in a permanent child-like state [8].

Our previous work shown that analyzing alpha band power of the electroencephalogram (EEG) signals could provide detail understanding of children with porn addiction $[9,10]$. Such analysis triggers us to study the effect of porn addiction to learning disorders. In this paper we limit learning disorders to three types mainly: dyslexia, attention deficit and hyperactivity disorder (ADHD) and autistic spectrum disorder (ASD). Based on the finding, we propose the use of neurophysiological analysis to investigate relationship of LD to porn.

This paper is organized in the following manner. Section 2 presents the literature review on learning disorder, porn addiction and EEG used to capture brain signals. The research methodology is outlined in section 3. In section 4, experimental results on the neurophysiological analysis of porn addiction to learning disorders are discussed. Subsequently, this paper concludes with summary and future work in section 5.

\section{LITERATURE REVIEW}

\subsection{Learning disorder}

LD is defined to be a heterogeneous group of disorders with neurologically based processing problems that interfere the skills by significant difficulties in the acquisition of knowledge and skill [11, 12]. Most people with LDs can face unique challenges that are often pervasive throughout their lifespan and would require the support from others especially parents and teachers. The diagnostic criteria of ASD based on the newest publication of the diagnostic and statistical manual of mental disorders (DSM-5) are persistent deficits in social communication and social interaction and, restricted or repetitive in patterns of behavior, interests or activities [13]. According to statistics from centers for disease control and prevention (CDC) of autism and developmental disabilities monitoring (ADDM) Network, the percentage of children with ASD remains high at 1 in 68 [14].

Psychologists categorized ADHD as another form of learning disorder. ADHD is a disorder that affects children's focus and attention that may lead to a permanent disorder if it is not controlled. Turel and Bechara [15] points out that ADHD symptoms lead to a risky behavior. The inattentive of ADHD is high in sluggish cognitive tempo which is low in leadership and peer-directed relational, and overt aggression [16]. The inattentive ADHD youth are often wandering off, fails to sustain attention, appears not to listen to any instructions and experiences difficulties to focus in completing any task and can makes reckless actions and seems impatient. The National Institute of Neurological Disorders and Stroke (NINDS) defined dyslexia as a learning disorder that specifically cause problems with a person ability to read despite having a normal intelligence [17] with learning difficulty which include the phonological processing deficits and poor in language-based processing skills and speed [18]. The study by Swagerman et al. found that the variation in reading ability might be caused by the genetic factors [19].

\subsection{Previous works on learning disorder recognition using EEG biomarker}

The EEG analysis and classification have been used in several studies to help a better diagnosis of learning disorders. The frequency bands of EEG were filtered to measure specific criterion of learning disorders based on the suggestions by the previous studies. Currently, researchers in neuroscience developmental fields are actively pursuing the invention and implementation of relevant biomarkers to review both the social and cognitive brain development $[20,21]$. One of the common biomarkers is the use of EEG. Moreover, EEG activity also can be measured by the relative power or absolute power of EEG signals to differentiate abnormalities by referring to their frequency bands. Jun et al. [22] observed the U-shaped profile of abnormal functional connectivity pattern between ASD and healthy person. The theta 
and beta power are always lower than the alpha power for healthy participants while such situation is contradictory for the ASD participants.

Synder et al. proposed an integration of EEG biomarker together with a clinician`s ADHD evaluation to improve the accuracy of ADHD diagnosis with better criterion and certainty [23, 24]. Furthermore, a study by Van Doren et al. concludes that theta/beta training in ADHD children with the short-term of neurofeedback (NF) could be valuable and economical to study the NF-associated plasticity mechanisms in the clinical disorders [25]. Most of the recent studies suggested the use of theta band activities in the neurophysiological study for dyslexia by using the biomarker, EEG. According to Papagiannopoulou and Lagopoulos, an atypical linguistic network hallmarked by an increase of theta power and a dominance of theta activity in the left hemisphere [26]. The need for cognitive control is also realized by the frontal theta band activities over the mid-frontal cortex that reflect on a common computational use [27].

The reviews of EEG-based learning disorder have been summarized in Table 1. Additionally, as noted by Jäncke and Alahmadi, the EEG theta over beta and theta over alpha ratios were higher and the EEG oscillations were slower in children with learning disorders compared to typically healthy children by using the proposed method, group independent component analysis (gICA) model [28]. Hence, it shows potential of EEG use as an effective tool for early detection of learning disorders.

Table 1. Comparative table of EEG-based learning disorder approaches

\begin{tabular}{|c|c|c|c|}
\hline Data & Aspects & Methods & Results \\
\hline ASD: Resting state EEG [21] & $\begin{array}{l}\text { Spectral power, coherence } \\
\text { and hemispheric } \\
\text { asymmetry }\end{array}$ & $\begin{array}{l}\text { U-Shaped profile of } \\
\text { abnormalities }\end{array}$ & $\begin{array}{l}\text { Excessive power in low-frequency and } \\
\text { high-frequency bands, and enhanced power } \\
\text { in left hemisphere for resting state. }\end{array}$ \\
\hline $\begin{array}{l}\text { ASD: Children Neurofeedback of } \\
\text { EEG [20] }\end{array}$ & $\begin{array}{l}\text { The changes in the relative } \\
\text { power of EEG bands }\end{array}$ & Ratio of Alpha/Beta & $\begin{array}{l}\text { Neurofeedback is an effective method for } \\
\text { altering EEG characteristics associated with } \\
\text { ASD }\end{array}$ \\
\hline $\begin{array}{l}\text { ADHD: Clinician's } \\
\text { evaluation [22] }\end{array}$ & Criterion E certainty & Ratio of Theta/Beta & $\begin{array}{l}\text { Greater criterion E certainty supports } \\
\text { accuracy of ADHD diagnosis }\end{array}$ \\
\hline ADHD: EEG Neurofeedback [24] & $\begin{array}{l}\text { Short-term setting } \\
\text { Neurofeedback }\end{array}$ & Ratio of Theta/Beta & $\begin{array}{l}\text { Short-term NF may be a valuable and } \\
\text { economical tool }\end{array}$ \\
\hline DYSLEXIA: Children EEG [25] & EEG power spectra & & Dominance of theta activity \\
\hline YSLEXIA: EEG frontal [26] & Theta Bands similarities & \multicolumn{2}{|c|}{$\begin{array}{l}\text { Theta bands over the mid-Theta band activities reflect on a common } \\
\text { frontal cortex } \\
\text { computational used for cognitive control }\end{array}$} \\
\hline
\end{tabular}

\section{RESEARCH METHOD}

This section discusses on the methods used in the study including the data collection, participants questionnaire and data analysis. Figure 1 illustrates the overall experimental process. There are two types of data collected from two different sources of EEG signals and questionnaire. The participants are needed to answer the questionnaire prior to EEG data collection. Such approach is the typical method used by the psychologists to identify 1) whether the participants are porn addict or not and 2) the participants experienced learning disorder or not. Once the data collection process is completed, relevant features are extracted. These features are then used for classification purposes. Figure 1 shows the block diagram of the way the correlation between the porn addiction and the learning disorders were carried out. As can be seen from Figure 1, the same data were used to analyze porn addiction and learning disorders.

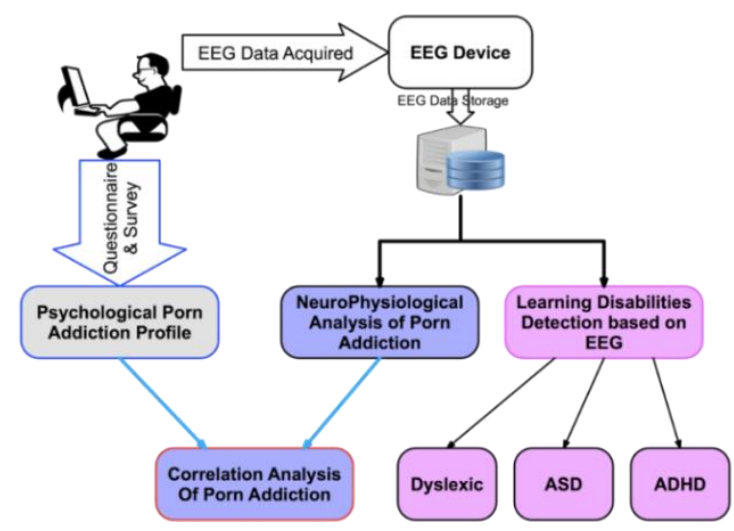

Figure 1. Block diagram of the neuro-psychological correlation between porn addiction and learning disorders 


\subsection{EEG data collection}

The EEG data collection involved 14 participants consisting of 9 males and 5 females with age ranging between 9 to 13 years old. The 19-channels EEG device from BrainMarker was used; capturing signals from the following channels, namely; Fp1, Fp2, F3, F4, F7, F8, C3, C4, P3, P4, P7, P8, T7, T8, O1, $\mathrm{O} 2, \mathrm{Pz}, \mathrm{Cz}$ and $\mathrm{Fz}$. The $\mathrm{AFz}$ and $\mathrm{FCz}$ channels were used as ground and reference respectively. The EEG device was used to acquire and collect data at resting state, eyes closed and eyes opened, before and after the experiments, executive visual functions to determine subject perceptions of objects and emotion recognition. Data were acquired and collected together with the children from Yayasan Kita dan Buah Hati (YKBH), Jakarta, Indonesia and was assisted by the appointed psychologists to perform the questionnaire for detection of porn addiction using psychological instruments $[9,10,12]$.

\subsection{Questionnaire}

The questionnaire session for porn addiction takes place before the EEG data collection was performed during the same day. This session was handled and validated by the psychological team from YKBH to detect whether the participants are considered as porn addicted or otherwise. The summarized results for porn addiction were finalized by comparing both porn addiction detection via EEG and the questionnaire.

\subsection{Data analysis}

EEG signals analysis included the preprocessing followed by bandpass filtering. The preprocessing removes the artifacts and unwanted data such as noise and poor signal. Bandpass filtering extracts the Theta with 4-8 Hz, Alpha with 9-13 Hz and Beta with 14-30 Hz [21, 28] to be used for processing with $250 \mathrm{~Hz}$ sampling frequency [10]. The learning disabilities detections were based on previous study as suggested by the literatures [20-22, 24-26]. Pornography addiction can be recognized by analyzing power of frontal cortex $[9,10,12]$, for ASD the ration of alpha and beta power $\left(\alpha^{2} / \beta^{2}\right)[20,21]$, for ADHD the ratio of theta over beta power $\left(\theta^{2} / \beta^{2}\right)[22,24]$ and for dyslexic the ratio of theta power on the left brain compare to the right brain $(\theta)[25,26]$.

\section{RESULTS AND DISCUSSION}

It is possible to use neurophysiological method to detect individual brain abnormalities as indicated from the literature review. In this study, all learning disorders detection was carried out using the time domain analysis based on power of the various EEG signal band as suggested from the literatures [20-22, 24-26] as well as porn addiction detection [9, 10, 12]. Subsequently, the correlation of LD and porn addiction is measured to see the relationship between these two variables. Table 2 presented the recognition results of LD recognition. EC and EO representing eyes closed and eyes opened respectively. In the ASD test, the N, L, U and 7 shapes are produced when the delta, theta, alpha, beta and gamma are plotted. If the shape is in the form of $\mathrm{L}$ or $\mathrm{U}$, it indicates the potential of participants to have ASM. Based on the result in Table 2, participant $\mathrm{S} 2, \mathrm{~S} 8, \mathrm{~S} 10$, and $\mathrm{S} 14$ are recognized as having ASD.

Table 2. The relations of porn addiction with learning disorders

\begin{tabular}{ccccccccc}
\hline \multirow{2}{*}{ Participants } & \multirow{2}{*}{ Gender } & \multicolumn{2}{c}{ ASD Test } & \multicolumn{2}{c}{ ADHD Test } & \multicolumn{2}{c}{ Dyslexic Test } & Porn Addiction \\
\cline { 3 - 7 } & & EC & EO & EC & EO & EC & EO & Addicted \\
\hline S1 & Male & N & 7 & 0.8 & 1.6 & 1.0 & 1.0 & Addicted \\
S5 & Male & N & U & 0.8 & 0.8 & 1.0 & 1.0 & Addicted \\
S6 & Male & 7 & U & 0.5 & 0.8 & 0.9 & 1.1 & Addicted \\
S9 & Female & 7 & U & 0.9 & 0.8 & 0.6 & 0.6 & Addicted \\
S10 & Female & L & U & 0.7 & 0.7 & 1.0 & 1.0 & Addicted \\
S11 & Female & N & L & 1.3 & 0.8 & $\mathbf{1 . 2}$ & $\mathbf{1 . 2}$ & Addicted \\
S14 & Male & L & U & 0.7 & 1.0 & $\mathbf{1 . 5}$ & $\mathbf{1 . 2}$ & Addicted \\
S2 & Female & L & U & 0.7 & 0.7 & 0.9 & 0.8 & Not Addicted \\
S3 & Female & N & N & $\mathbf{1 . 7}$ & $\mathbf{1 . 7}$ & 1.0 & 1.0 & Not Addicted \\
S4 & Male & 7 & L & 0.9 & 1.2 & 1.0 & 0.9 & Not Addicted \\
S7 & Male & N & U & 1.0 & 1.0 & 1.0 & 1.0 & Not Addicted \\
S8 & Male & U & U & 0.7 & 0.7 & 1.0 & 1.0 & Not Addicted \\
S12 & Male & N & L & 1.0 & 1.0 & 0.9 & 0.9 & Not Addicted \\
S13 & Male & 7 & 7 & 1.1 & 1.1 & $\mathbf{1 . 2}$ & $\mathbf{1 . 3}$ & Not Addicted \\
\hline
\end{tabular}

Note: Bold ASD test=ASD, Bold ADHD test=Highest value of ADHD test, Bold Dyslexic test=Dyslexia

Moreover, there is a high possibility for the participant to have ADHD if his/her theta power is higher than beta power. If theta power divided by beta power resulting value of more than 1 , it shows that 
theta power is higher than beta power. The value in participants S3 indicates high value of ADHD test showing her tendency of having ADHD. Atypical linguistic network is found in children with dyslexia is characterized by a dominance of theta activity that implicating delayed maturation and abnormal hypoarousal mechanisms. Hence, if the difference of theta power in both left brain and right brain is larger than $20 \%$, there is a potential for dyslexic or similar learning disorder. From the experimental result, it is observed that participant S11, S13, and S14 are recognized as dyslexic.

Further analysis is carried out to validate the EEG model and questionnaire answers. The porn addiction trapezoidal diagram of Figure 2 shows the correlation of the psychological instrument detection to the EEG power distribution at the frontal. Blue lines indicated that the subjects are detected as porn addict by the psychological instruments while the red lines indicated as non-addict. The $\mathrm{x}$-axis shows normalized power at the frontal using range of 7,000 to 8,000 microwatt as a threshold. If the value of EEG power distribution is more than 8,000 microwatts, the participants are recognized as non-addict while value less than 7,000 microwatt is considered an addict. The trapezoidal curve shows that between 7,000 to 8,000 has the probability as shown by the y-axis. Based on Figure 2, participant with label of S10, S9, S1, S11, S6, S14, and S5 were detected as porn addicts while S4, S2, S7, S8, S3, S12 and S13 were recognized as non-addicts.

\subsection{ASD (alpha/beta)}

The use of alpha and beta bands to detect ASD among subjects is indicated in the literature [21]. Figure 2 shows the combination result of ASD correlated with porn addiction as indicated by Table 2 . In Figure 2, the red color representing ASD and the pink color representing mild ASD. In addition, black color denotes normal participants. From the experimental results, it is observed that subjects S10, S14, S2 and S8 are considered having ASD as indicated from Table 2. It is interesting to note that although participant S9, S6, S5 and S12 seems to have ASD for eyes opened as shown in Table 2, their ratios of alpha power over beta power show low consistency between the initial states as projected in Figure 2. This indicates the potential for respective participants of having mild ASD. Subsequently, majority of the ASD (including the mild ASD) subjects shown in Figure 2 are recognized as porn addict. Such loose correlation could exist since the frontal part of the brain involved executive functions, which also correlate to the fine motor movement of the ASD.

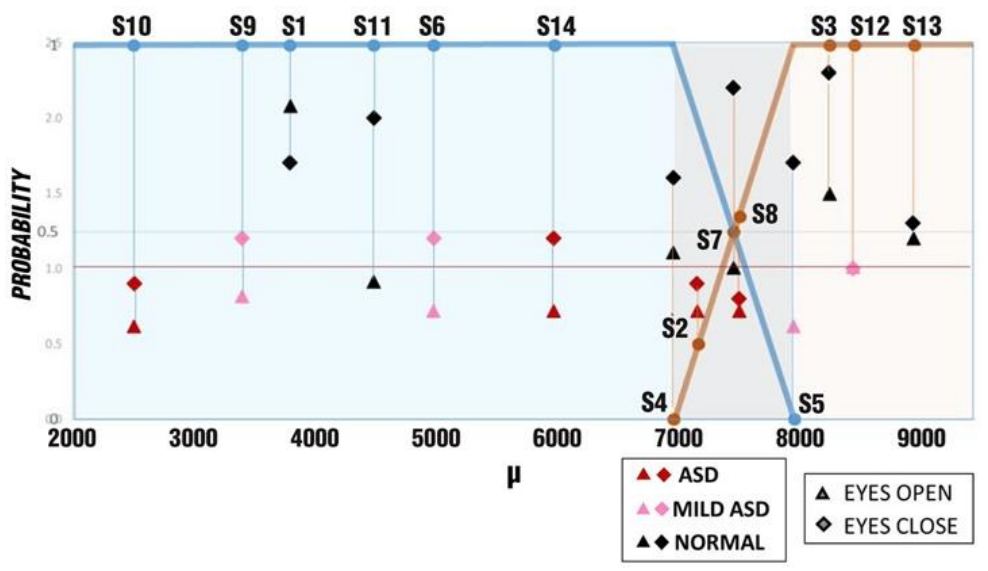

Figure 2. ASD detection over the trapezoidal diagram of porn addiction

\subsection{ADHD (Theta/Beta)}

The theta and beta bands training were suggested by the previous study for ADHD [24]. Figure 3 shows the result of ADHD correlated with porn addiction as referred to Table 2 . The green colour markers represent eyes closed and the purple colour marker represents eyes opened states. It is observed that the theta beta power ratio for all subject for eyes closed and eyes open are almost similar except for two subjects of S1 and S11. For the ADHD detection among all of the subject, the overall values of ADHD test by using theta/beta ratio are quite low. The highest value is 1.7 for both eyes closed and eyes open but it is still did not meet the criterion of ADHD. Based on the results, the consistency of the subjects' focus might be good as the results for both eyes closed and eyes open are almost the same. Therefore, the findings concluded that all of the subjects are free from ADHD diagnosis. 


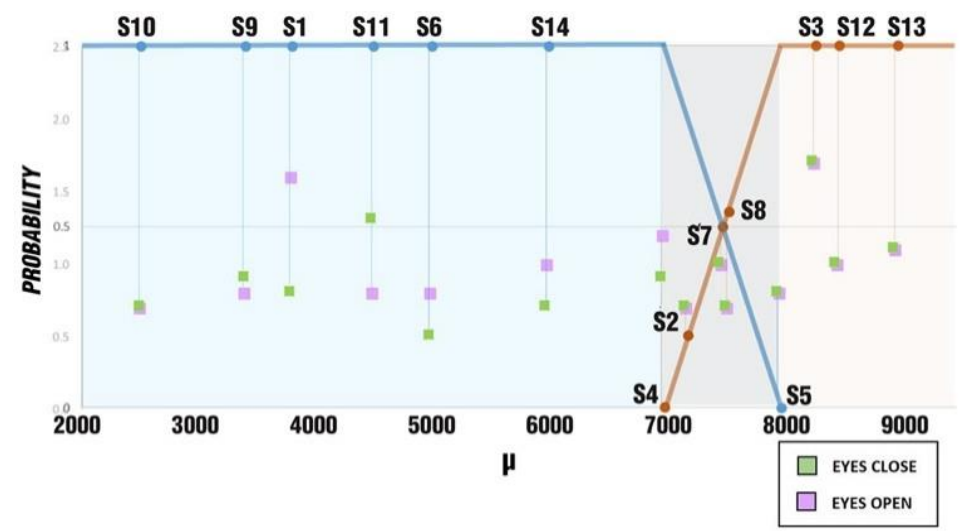

Figure 3. ADHD detection over the trapezoidal diagram of porn addiction

\subsection{Dyslexia (Theta)}

The increasing power of theta on the left hemisphere of the brain including the frontal can help to detect the possibility of a child having dyslexia [25, 26]. Thus, if the theta band power of the left brain is higher than the theta band power of the right brain, it may indicate the potential of a subject with dyslexia. From result of Table 2, is can be seen that only subject S11, S14 and S13 have their theta power on the left-brain higher than the right-brain. Such results indicate potential of dyslexia. The results are then mapped in Figure 4 on the porn addiction trapezoidal graph. The dark blue color markers indicating eyes closed and the yellow color markers as eyes opened. From Figure 4, the results for most of the subjects were almost identical especially for participants S10, S9, S1, S11, S7, S8, S5, S3 and S12. However, participant S6, S14, S4, S2, and S13 have a small difference between eyes closed and eyes opened. For dyslexia detection, participants S11, S14, and S13 yielded high ratios of the left-brain theta power over the right brain theta power. Such observation could be categorized in the dyslexic group. The experimental results show that there is no obvious relation between dyslexia and porn addiction as can be seen from Table 2 and Figure 4, hence, porn addiction cannot be correlated to dyslexia.

Subsequently, the EEG analysis of LD does not show any strong correlation with porn addiction as well. Such result indicates that porn addiction can happen to anybody regardless of their intelligence level. However, it is noted that there is a strong correlation between porn addiction and the power on the frontal area of the brain.

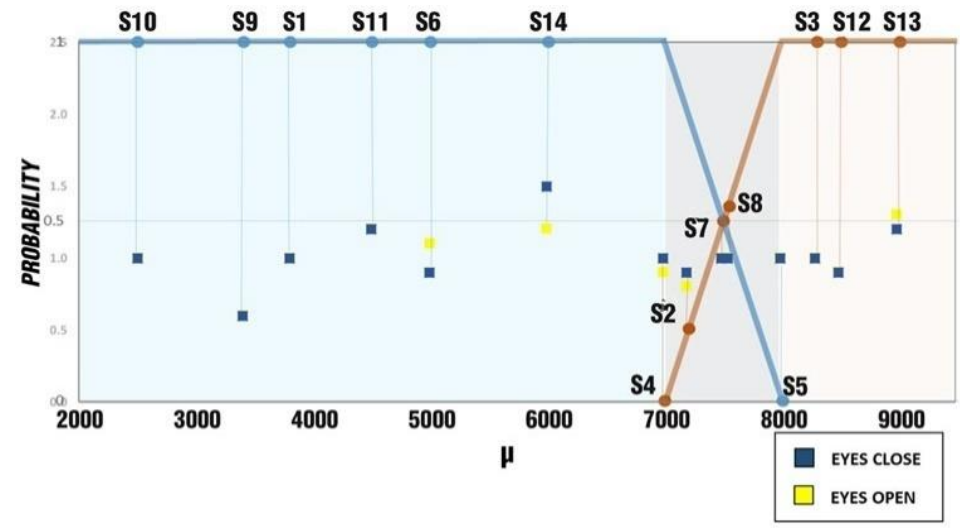

Figure 4. Dyslexia detection over the trapezoidal diagram of porn addiction

\section{CONCLUSION}

Based on the results and discussions, porn addiction seems to have some correlation with ASD but not directly observable with ADHD and dyslexia. Although this is only a preliminary research, it shows potential of using the EEG signals to identify porn addiction and correlating it to the different types of learning disorders. Further researches are needed to further understand about the ASD relationship to porn 
addiction, thus highlighting factors influencing ASD subjects to become addicted. Porn addiction does not have observable correlations between ADHD and dyslexia as the results presented were consistent between eyes opened and eyes closed for most subjects. Moreover, the findings also highlighted that there is no direct correlation of learning disorders to porn addiction based on the neurophysiological analysis. Porn addiction may be developed regardless of the brain developmental progress. Subsequently, this is the first work that tried to correlate between the porn addiction and learning disorders. To date, no one has yet to look at on this correlation which hopefully can help psychologist to further research in this particular area.

\section{ACKNOWLEDGEMENTS}

The authors would like to thank Universiti Teknologi MARA (UiTM), International Islamic University Malaysia (IIUM) and Ministry of Higher Education Malaysia (MOHE) for providing financial support through the Trans Disciplinary Research Grant Scheme TRGS (TRGS16-04-02-002) to conduct the work published in this paper.

\section{REFERENCES}

[1] UNICEF Malaysia, "Issue brief: children with disabilities in Malaysia," 2020. [Online]. Available at: https://www.unicef.org/malaysia/reports/issue-brief-children-disabilities-malaysia.

[2] Jabatan Kebajikan Masyarakat, "Laporan statistik jabatan kebajikan masyarakat," 2014. [Online]. Available at: http://www.jkm.gov.my/jkm/uploads/files/pdf/Buku\%20JKM\%202014.pdf.

[3] C. Cortiella and S. H. Horowitz, "The state of learning disabilities: facts, trends and emerging issues," New York: National Center for Learning Disabilities, vol. 25, pp. 2-45, 2014.

[4] A. Gershel, G. Mesibov, M. Sreckovic, K. M. Mogill, D. P. Sugrue, M. H. Allenbaugh, R. Wollert, A. Skelton, F. S. Berlin, E. Comartin, N. Dubin, C. Carpenter, J. Douard, P. Schultz, and M. Mahoney, "Caught in the web of the criminal justice system: Autism, developmental disabilities and sex offenses," Jessica Kingsley Publishers, London, pp. 64-70, 2017.

[5] M. P. McCabe and R. A. Cummins, "The sexual knowledge, experience, feelings and needs of people with mild intellectual disorder," Education and Training in Mental Retardation and Developmental Disabilities, vol. 31, no. 1, pp. 13-21, 1996.

[6] Malaysian Communications and Multimedia Comission, "Internet users survey," Mar 2020. [Online]. Available at: https://www.mcmc.gov.my/skmmgovmy/media/General/pdf/Internet-Users-Survey-2018-(Infographic).pdf.

[7] E. Martellozzo, A. Monaghan, J. R. Adler, J. Davidson, R. Leyva, and M. A. H. Horvath, "I wasn't sure it was normal to watch it," A quantitative and qualitative examination of the impact of online pornography on the values, attitudes, beliefs and behaviours of children and young people. London, UK: NSPCC, 2016.

[8] R. Young, N. Gore, and M. McCarthy, "Staff attitudes towards sexuality in relation to gender of people with intellectual disorder: A qualitative study," Journal of Intellectual and Developmental Disorder, vol. 37, no. 4, pp. 343-347, 2012.

[9] N. Kamaruddin, A. W. A. Rahman, and D. Handiyani, "Pornography addiction detection based on neurophysiological computational approach," Indonesian Journal of Electrical Engineering and Computer Science, vol. 10, no. 1, pp. 138-145, 2018.

[10] N. Kamaruddin, A. W. A. Rahman, and D. Handiyani, "Neuro-physiological porn addiction using machine learning approach," Indonesian Journal of Electrical Engineering and Computer Science, vol. 16, no. 2, pp. 964-971, 2019.

[11] D. D. Hammill, J. E. Leigh, G. McNutt, and S. C. Larsen, "A new definition of learning disabilities," Learning Disorder Quarterly, vol. 11, no. 3, pp. 217-223, 1987.

[12] N. Kamaruddin and A. W. A. Rahman, "Brain developmental disorders' modelling based on preschoolers neuro-physiological profiling," Indonesian Journal of Electrical Engineering and Computer Science, vol. 12, no 2, pp. 542-547, 2018.

[13] C. D. Mercer, LuAnn Jordan, D. H. Allsopp, and A. R. Mercer, "Learning disabilities definitions and criteria used by state education departments," Learning Disorder Quarterly, vol. 19, no. 4, pp. 217-232, 1996.

[14] American Psychiatric Association, "Diagnostic and statistical manual of mental disorders: DSM-5," American Psychiatric Pub, 2007.

[15] O. Tureland and A. Bechara, "Social networking site use while driving: ADHD and the mediating roles of stress, self-esteem and craving," Frontiers in Psychology, vol. 7, no. 455, 2016.

[16] S. A. Marshall, S. W. Evans, R. B. Eiraldi, S. P. Becker, and T. J. Power, "Social and academic impairment in youth with ADHD, predominately inattentive type and sluggish cognitive tempo," Journal of Abnormal Child Psychology, vol. 42, no. 1, pp. 77-90, Jan. 2014.

[17] National Institute of Neurological Disorders and Stroke, "Dyslexia information page," [Online]. Available at: https://www.ninds.nih.gov/Disorders/All-Disorders/Dyslexia-Information-Page.

[18] R. L. Peterson and B. F. Pennington, "Developmental dyslexia," Annual Review of Clinical Psychology, vol. 11, pp. 283-307, Mar. 2015.

[19] S. C.Swagerman, E. van Bergen, C. Dolan, E. J. C. de Geus, M. M. G. Koenis, H. E. H. Pol, and D. I. Boomsma, "Genetic transmission of reading ability," Brain and Language, vol. 172, pp. 3-8, 2017. 
[20] K. J. Varcin and C. A. Nelson, "A developmental neuroscience approach to the search for biomarkers in autism spectrum disorder," Current Opinion in Neurology, vol. 29, no. 2, pp. 123-129, Apr. 2016.

[21] Y. Wang, E. M. Sokhadze, A. S. El-Baz, X. Li, L. Sears, M. F. Casanova, and A. Tasman, "Relative power of specific eeg bands and their ratios during neurofeedback training in children with autism spectrum disorder," Frontiers in Human Neuroscience, vol. 9, art. no. 723, pp. 1-11, 2016.

[22] J. Wang, J. Barstein, L. E. Ethridge, M. W. Mosconi, Y. Takarae, and J. A. Sweeney, "Resting state EEG abnormalities in autism spectrum disorders," Journal of Neurodevelopmental Disorders, vol. 5, art. no. 24, pp. 1-14, 2013.

[23] S. M. Snyder, T. A. Rugino, M. Hornig, and M. A. Stein, "Integration of an EEG biomarker with a clinicians ADHD evaluation," Brain and Behavior, vol. 5, no. 4, pp. 1-17, May 2015.

[24] M. R. Mohammadi, A. Khaleghi, A. M. Nasrabadi, S. Rafieivand, M. Begol, and H. Zarafshan, "EEG classification of ADHD and normal children using non-linear features and neural network," Biomedical Engineering Letters, vol. 6, no. 2, pp. 66-73, 2016.

[25] J. V. Doren, H. Heinrich, M. Bezold, N. Reuter, O. Kratz, S. Horndasch, M. Berking, T. Ros, H. Gevensleben, G. H. Moll, and P. Studer, "Theta/beta neurofeedback in children with ADHD: Feasibility of a short-term setting and plasticity effects," International Journal of Psychophysiology, vol. 112, pp. 80-88, 2017.

[26] E. A. Papagiannopoulou and J. Lagopoulos, "Resting state EEG hemispheric power asymmetry in children with dyslexia," Frontiers in Pediatrics, vol. 4, art. no. 11, pp. 1-7, Feb. 2016.

[27] J. F. Cavanagh and M. J. Frank, "Frontal theta as a mechanism for cognitive control," Trends in Cognitive Sciences, vol. 18 , no. 8, pp. 414-421, 2014.

[28] L. Jäncke and N. Alahmadi, "Resting state EEG in children with learning disabilities," Clinical EEG and Neuroscience, vol. 47, no. 1, pp. 24-36, Jan. 2016.

\section{BIOGRAPHIES OF AUTHORS}
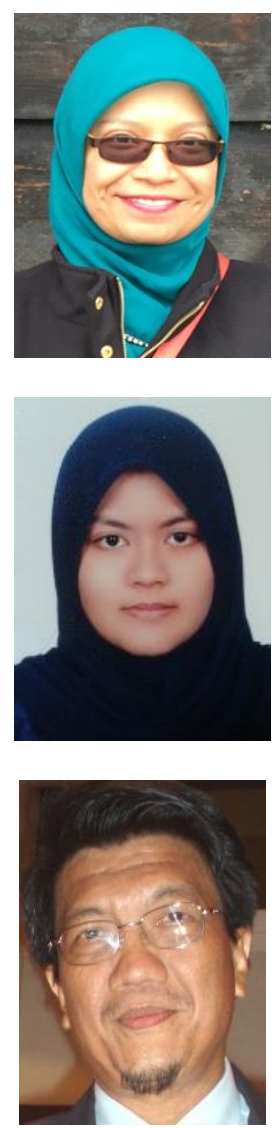

Norhaslinda Kamaruddin currently holds a post of associate professor in Faculty of Computer and Mathematical Sciences, Universiti Teknologi MARA (UiTM), Malaysia. She served UiTM since 2011. She received her bachelor's degree in Information Technology (Computer Science) from Universiti Kebangsaan Malaysia in 2001 followed by her Master of Software Engineering from Malaya University in 2006. In 2013, she is awarded with Doctor of Philosophy (Computer Engineering) from Nanyang Technological University (Singapore) focusing on computational intelligence especially on Affective Computing. She is very active in research fields of affective computing, speech emotion recognition, neuro-cognitive informatics, big data analytics and driver behavioral study.

Nurul Izzati Mat Razi received her degree in Information Technology in 2015, Master of Computer Science by Research in 2018 and currently doing PhD in Computer Science at the International Islamic University Malaysia (IIUM) Malaysia. Prior to that, she assisted several EEG projects at the Pervasive Computing for Brain Development Research Group as the data collector. She is done her master with the research of Neuro-finance and currently worked on the research of learning disabilities detection among children.

Abdul Wahab received the Degree from the University of Essex, Essex, U.K., in 1979, the M.Sc. degree from the National University of Singapore, Singapore, in 1987, and the Ph.D. degree from Nanyang Technological University, Singapore. His research has been in the areas of telecommunication, signal processing, and artificial intelligence. He was with Hewlett Packard Singapore, Singapore, as a Research and Development Project Manager both in CO, USA. He joined Nanyang Technological University in 1990, where he was an Associate Professor, before joining the International Islamic University of Malaysia, Malaysia, as a Professor, in 2009. $\mathrm{He}$ has authored over 100 conference papers, journal papers, patents, and book chapters in the areas of digital and optical computing, signal processing, and artificial intelligence. 